\title{
The Role of Bystander Perceptions and School Climate in Influencing Victims' Responses to Bullying: To Retaliate or Seek Support?
}

\author{
Sarah Lindstrom Johnson, ${ }^{1}$ Tracy Evian Waasdorp, ${ }^{2}$ Katrina Debnam, ${ }^{2}$ \\ and Catherine P. Bradshaw ${ }^{2}$ \\ ${ }^{1}$ Johns Hopkins School of Medicine, 200 North Wolfe Street, Baltimore, MD 21287, USA \\ ${ }^{2}$ Johns Hopkins Center for the Prevention of Youth Violence, Johns Hopkins Bloomberg School of Public Health, \\ 624 North Broadway, Baltimore, MD 21205, USA
}

Correspondence should be addressed to Sarah Lindstrom Johnson; slj@jhmi.edu

Received 27 February 2013; Accepted 23 May 2013

Academic Editor: Byongook Moon

Copyright (C) 2013 Sarah Lindstrom Johnson et al. This is an open access article distributed under the Creative Commons Attribution License, which permits unrestricted use, distribution, and reproduction in any medium, provided the original work is properly cited.

In order to reduce aggressive responses to bullying, schools nationwide have begun to implement bullying prevention programs that advise students to tell an adult, walk away, or ask the bully to stop. While previous work has demonstrated that individual differences (e.g., gender) influence the likelihood of students choosing assertive responses in lieu of aggressive responses, there has been less research on understanding how aspects of the school climate affect students' responses to bullying. This study explores how perceptions of teacher and student intervention as well as perceptions of school safety and connectedness influence students' likelihood of responding aggressively (i.e., retaliating) or seeking support from an adult. These data come from an online school climate survey administered to 25,308 students in 58 high schools. Three-level hierarchical linear modeling was conducted on a subset of 6,493 students who reported being bullied in the past year. Results suggest that bystander perceptions and school climate play a role in influencing students' responses to bullying, both by decreasing the likelihood of victims using an aggressive response and increasing their likelihood of seeking support from school staff. Interventions that focus more holistically on changing school climate may better interrupt the cycle of violence.

\section{Introduction}

Bullying is a significant concern in US high schools, with $20 \%$ of youth reporting being bullied in the past year [1]. Bullying is a form of repeated peer victimization that involves a real or perceived power imbalance [2]. A burgeoning body of evidence suggests serious adverse effects of bullying on the social-emotional wellbeing, academic achievement, and health of the victim $[3,4]$. Because of these negative consequences as well as the disruption to the learning environment caused by bullying, schools nationwide have begun to implement bullying prevention programs. Most bullying prevention programs aim to change school norms around bullying, such as addressing the behaviors of teachers, bystanders, and victims. For example, several programs encourage schools to adopt norms in which students and staff are more vigilant to bullying and are willing to assist victimized students. While there is evidence that schoolbased antibullying programming can improve school climate $[5,6]$, less is known about how school climate influences victims' experiences of bullying, particularly their response to victimization.

This is an important gap in the literature as victims' responses to bullying have been shown to moderate the negative consequences of victimization [7-9]. In addition, certain responses, such as a retaliatory response, perpetuate violence; they also cause further disruption to the learning environment and negatively affect school climate. Because of this, bullying prevention programs commonly advise victims to tell an adult, walk away, or ask the bully to stop (e.g., [10]). 
Gender, developmental differences, and the form of bullying have all been found to influence the likelihood of students choosing these more relational and assertive responses in lieu of aggressive responses [11]. However, there has been less research on understanding how potentially modifiable factors such as bystander perceptions and aspects of the school climate influence students' responses to bullying. This study attempted to fill that void by exploring how perception of teacher and student intervention in the bullying situation as well as two aspects of school climate (perception of school safety and connectedness) influence students' likelihood of (1) responding aggressively (i.e., retaliating) or (2) seeking support from an adult. The role of gender in moderating the relationship between bystander perceptions and school climate and responses to bullying was also explored.

\section{Victims Responses to Bullying}

Youth employ a wide variety of strategies to respond to bullying [12-14]. A recent study of frequently victimized high school students identified different patterns of responses to bullying, including a passive response pattern, where youth were more likely to endorse walking away or ignoring than other strategies, as well as an aggressive response pattern, where youth tended to report displaying aggressive strategies, such as bullying, fighting, or arguing in response to their victimization [11]. A third pattern also emerged, referred to as the "undifferentiated" pattern, whereby victims acknowledged use of variety of different responses to bullying [11]. Not surprisingly, youth with an aggressive response pattern were more likely to exhibit externalizing problems (e.g., aggression, retaliation); interestingly, the youth with an undifferentiated pattern were more likely to exhibit internalizing problems, such as symptoms of depression [11]. Although these findings are correlational, they do suggest that youths' responses to bullying may covary with socioemotional problems.

Unfortunately, there is limited research examining the predictors of students' responses to bullying. A broader literature exploring coping with violence suggests that girls are more likely to use relational and assertive responses $[9,15$, 16], whereas boys are more likely to use distancing responses or respond with aggression $[15,17,18]$. The current study seeks to extend these findings by exploring youths' responses to bullying, as well as examining the influence of the school environment. We adopt a socioecological perspective and conceptualize bullying as an interaction between an individual bully and a victim that unfolds within a context [19].

\section{The Influence of Bystander Perceptions}

Bullying prevention programs and parents often instruct students to "tell an adult" when they are victimized [10,20]. Although this is a widely advocated response to bullying, a study of high school students found only $45 \%$ of youths reported using this option [21]. One potential reason for students' reluctance to inform adults may be students' perceptions of adults' willingness to intervene on their behalf
[22]. Factors such as perceived seriousness of the bullying, amount of empathy for the victim, personal victimization experiences, and behavioral management self-efficacy have been shown to predict teachers' responses to bullying [2325]. A recent survey conducted by the National Education Association found that while the majority of educators are concerned about bullying, they lack training in the appropriate response to bullying [26].

There is a growing literature aiming to understand the role of the peer group in bullying, as peer witnesses are present in most instances of bullying [27-29]. One observational study found that when bystanders reacted on behalf of the victim they were effective in stopping the bullying episode [27]. Yet, while many youth report intentions to defend a peer in a bullying situation [30-33], actual defending behavior is less common $(<20 \%)$ [34]. In a study of 4 th11th graders, younger students and girls were more likely to be "defenders of the victim" [35]. Most of the literature on bystander effects has focused on understanding how norms of bullying influence the behaviors of the bystanders. Less is known about how bystander behaviors influence bullying victims' responses to bullying events. A recent study suggests that bullying victims who are defended by their peers are less anxious, less depressed, and have higher self-esteem [36]. More needs to be known about how victims' perception of peer intervention influences their decision about how to respond to bullying.

\section{The Influence of School Climate}

Although much of the research has focused on individuallevel correlates of bullying, including gender and grade level, there is increasing interest in the context of bullying [37,38]. Social disorganization theory [39] highlights the potential influence of contextual and organizational factors on the risk for involvement in aggression. For example, structural aspects of a community, such as concentration of poverty and residential mobility, affect the level of organization present within an environment and the collective efficacy of its residents [40]. A similar process likely occurs within a school environment, whereby school-level factors that challenge school functioning and stability interfere with a school's collective efficacy and ability to effectively enforce norms of behavior [41-43]. In fact, several school- and classroomlevel indicators of disorder (e.g., poverty level, school size, poor classroom management, and concentration of students with behavior problems) have been linked with diminished perceptions of safety and climate $[23,37,44]$. Additionally, studies have shown that indicators of social control, such as the presence of adults and lack of physical deterioration, decrease the belief that violence is acceptable and will go unnoticed $[45,46]$.

Research has highlighted the link between a negative school climate and bullying, thereby suggesting that, in schools where there are shared beliefs and attitudes supporting bullying, aggression and peer victimization become the norm [22]. Consistent with the social cognitive perspective $[47,48]$, these shared beliefs likely influence students' 
responses to bullying [22]. For example, high levels of aggressive behavior may cause students to infer that adults do not have control over the environment and, therefore, might encourage a retaliatory response to bullying [37, 43, 49]. Contrary to this, feelings of connectedness to adults at the school have been shown to encourage students to seek help from adults in response to bullying [50]. Some research suggests potential gender differences in the influence of school climate on student behavior [51].

In the current study, we explored how perceptions of staff and student bystander behaviors as well as two school climate variables, safety and connectedness, influenced students' responses to bullying. We investigated how these perceptions are related to bullying victims' decision to respond aggressively or to tell an adult. We hypothesized that more favorable perceptions of bystander intervention as well as school safety and connectedness would be associated with a decreased likelihood of victims responding aggressively and an increased likelihood of seeking support. Because of the potential for this influence to differ by gender [11], we also conducted exploratory analyses on gender differences in the influence of bystander perceptions and school climate on students' responses to bullying. Specifically, given the higher levels of physically aggressive behavior among boys noted in previous studies [14, 31], we hypothesized that boys would more likely endorse aggressive responses to bullying (e.g., retaliating). In contrast, we expected that girls would be more likely than boys to seek support from adults.

\section{Methods}

5.1. Sample. Data come from 58 Maryland high schools in 12 counties that were participating in a state-wide project focused on measuring and improving school climate, called the Maryland Safe and Supportive Schools Initiative $\left(\mathrm{MDS}^{3}\right)$, which began in 2011. Data were collected from 25,308 adolescents via a web-based survey as a baseline assessment of the project. An average of 23.75 classrooms per school was randomly selected to participate in the data collection. Consistent with the definition by Olweus [10] and the Centers for Disease Control [52], the survey included a definition of bullying, which read, "A person is bullied when he or she is exposed, repeatedly and over time, to negative actions on the part of one or more other persons. Bullying often occurs in situations where there is a power or status difference. Bullying includes actions like threatening, teasing, name-calling, ignoring, rumor spreading, sending hurtful emails and text messages, and leaving someone out on purpose." Since we were interested in adolescents' responses to bullying, the sample was restricted to the 6,493 students who reported being a victim by bullying in the past year. Youth and school demographic characteristics for the current analyses are presented in Table 1, with comparative information available for those students that did not report experiencing bullying $(n=18,815)$ in the past year.

5.2. Procedures. Schools' participation in the $\mathrm{MDS}^{3}$ project was voluntary. Districts were approached for participation by the Maryland State Department of Education (MSDE). Upon expressing interest in the $\mathrm{MDS}^{3}$ Initiative, district-specific principal meetings were conducted to obtain school-level and principal commitment to the project. The anonymous, online survey was administered using a passive consent process and youth assent process, and all participation was voluntary. Letters were sent home to parents providing information about the survey and the larger initiative. The survey was administered online in language arts classrooms to students in grades 9 through 12 . School staff administered the survey following a written protocol developed by the universitybased research team. The nonidentifiable data were obtained from MSDE and analysis of the data approved by the researchers' Institutional Review Board.

5.3. Measures. The $\operatorname{MDS}^{3}$ Climate Survey was developed by the Johns Hopkins Center for Youth Violence Prevention in collaboration with project partners [53]. Researchers from the center undertook a comprehensive review of the literature on measures of safety and youth violence. The self-report measure was used to assess all student-level variables as well as the overall school climate score. All data come from a single time point.

\subsubsection{Individual Level}

Youth Demographic Characteristics. Participating adolescents responded to a series of questions regarding their basic demographic characteristics, including grade, gender, and racial/ethnic category (see Table 1 for demographics).

Victimization Frequency. Students reported the frequency of their victimization experience, "In the past 30 days, how often have you been bullied." Answer choices included several times a week, once a week, 2-3 times a month, 1 time a month, and not at all. We dichotomized this variable, 2 or more times a month versus 1 or less (e.g., those that responded they were bullied in the past year, but were bullied 1 or less times in the past 30 days).

Response to Bullying. Students' responses to bullying were assessed by a single question ("What did you do when you were bullied?"), to which they could endorse multiple responses. Students responded to this question by either indicating whether they utilized a response (0) or did not utilize a response (1). Response choices utilized for this study include (a) bullied that person back, (b) got into an argument, (c) got into a physical fight, (d) hit/kicked/or pushed the bully, (e) bullied someone else, and (f) told an adult at school. Consistent with prior uses of this measure $[11,54]$ the aggressive response choices (i.e., bullied that person back, got into an argument, got into a physical fight, hit/kicked/or pushed the bully, and bullied someone else) were collapsed into using an aggressive response. The remaining response choice was labeled "seeking adult support."

Bystander Intervention. Students' perception of the likelihood that a staff member would intervene in a bullying situation 
TABLE 1: Demographic characteristics including comparison by victimization status.

\begin{tabular}{lccc}
\hline & Victims & Nonvictims & Test statistic \\
& $N=6493(25.7)$ & $N=18,815(74.3)$ & $92.4^{* * *}$ \\
White $^{\mathrm{a}}$ & 58.7 & 51.6 & $45.9^{* * *}$ \\
Male & 46.2 & 51.2 & $118.3^{* * *}$ \\
11th and 12th graders (versus 9th and 10th) & 37.7 & 45.6 & $24.5^{* *}$ \\
Students intervene & $1.91(0.89)$ & $2.23(.87)$ & $29.4^{* * *}$ \\
Adults intervene & $2.45(1.00)$ & $2.85(.90)$ & $43.9^{* * *}$ \\
Safety & $2.67(.69)$ & $3.06(.57)$ & $29.9^{* * *}$ \\
Connectedness & $2.48(.65)$ & $2.75(.56)$ & \\
\hline
\end{tabular}

Notes. ${ }^{\mathrm{a}}$ Dichotomous variables were examined using chi-square analyses; continuous variables were examined using $t$-tests. ${ }^{* *} P \leq .01,{ }^{* * *} P \leq .001$.

was assessed by asking whether "Adults at this school try to stop bullying." Perception of peer intervention was assessed by asking a parallel question, "Students at this school try to stop bullying." Students responded on a scale with response options ranging from 1 (strongly agree) to 4 (strongly disagree). Items were reversed coded so that higher values indicated a greater belief in adult and student intervention.

Safety. Four items assessed students perception of the safety of the school environment $[37,43]$. These items both included students feelings of safety at school and going to and from school. Students responded on a scale with response options ranging from 1 (strongly agree) to 4 (strongly disagree). Students were also asked their perception of the extent of a problem their school had with students' fighting and students' carrying weapons to schools. Students responded on a scale with response option ranging from 1 (large problem) to 4 (not a problem). Items were reversed coded as needed and then averaged such that a higher scored indicated a greater safety $(\alpha=.72)$.

Connectedness. Ten items assessed students perceptions of their connection with the school environment [55]. Five items focused on relationships with teachers (e.g., my teachers care about me), two items assessed feelings of belonging (e.g., I feel like I am a part of this school), and three items focused on peer relationships (e.g., students help one another). Responses were provided on a 4-point scale from 1 (strongly disagree) to 4 (strongly agree). Items were averaged such that a higher score indicate a greater connectedness $(\alpha=.88)$.

\subsubsection{School Level}

School Climate. Following the US Department of Education's model [56] that defines three core aspects of school climate: safety, engagement, and environment, an overall measure of each school's climate was calculated. This measure included 71 items measuring 11 different domains of school climate assessed by the $\mathrm{MDS}^{3}$ survey including physical safety, bullying, social-emotional wellbeing, substance use, connectedness, academic emphasis, parent involvement, culture of inclusion, order and discipline, physical environment, and support services [53,57]. Each individual scale had an acceptable internal consistency in the current sample ( $\alpha=.70-.87$ ). Scales were reverse coded such that higher levels of the scale indicate a better school climate (i.e., lower levels of bullying and substance use) and then aggregated. Although we were interested in specifically school-level perceptions of both safety and connectedness, collinearity of these variables at the school level precluded us from conducting analyses including both variables in the model simultaneously; therefore, we utilized a more global measure of school climate.

School-Level Demographic Indicators. A number of schoollevel demographic variables were obtained from the Maryland State Department of Education for inclusion in the models as school-level covariates. Those variables were the student/teacher ratio, the percentage of students eligible for Free and Reduced Meals, the percent of minority students attending the school, the percentage of students who received an out of school suspension, and the percent of minority students attending the school.

5.4. Missing Data. Descriptive analysis found very little missing data ( $<5 \%$ of each of the included variables) at the individual level and no missing data at the classroom or school level. Our analyses assume data are missing at random (MAR), which is based on the assumption that the reason for missingness is not related to the missing value itself or is deemed random after controlling for the variables that are observed [58]. Significant differences by demographic characteristics were found; males, younger students, and white students were more likely to be missing data on school climate variables. These demographic variables were included as controls in the analyses. The analyses were conducted using the HLM 7.0 software [59], which adjusts parameter estimates for attrition using full-information maximum-likelihood (FIML) estimation, a widely recognized and appropriate means of handling missing data [60] under the assumption that data are MAR [61].

5.5. Overview of the Analyses. Three-level hierarchical linear models were conducted in the HLM 7.0 software [61] to examine the association of bullying victims' perception of bystander behaviors and school climate with the decision to respond aggressively or to tell an adult; these analyses 
accounted for the nested nature of the data where students were nested in classrooms, nested in schools. All variables were assessed for collinearity, which resulted in a decision to not include perception of staff and peer intervention and perception of school safety and connectedness at the school level. Variables included at level 1 were age, gender, race, perception of staff and peer intervention, and perception of school safety and connectedness. All variables at level 1 were tested for randomly varying slopes [61] and grand-mean centered [62]. At level 2, we accounted for classroom-level nesting of students. At level 3, we included student-teacher ratio, percent FARMS, percent minority, percent suspended, and overall school climate. All level 3, variables were grandmean centered. Below is a sample model used in our analyses:

$$
\begin{aligned}
\eta_{i j k}= & \gamma_{000}+\gamma_{001} \\
& * \text { STUDENT TEACHER }_{k} \\
& +\gamma_{002} \text { FREE AND REDUCED MEALS } \\
& +\gamma_{003} * \text { SUSPENSION }_{k}+\gamma_{004} \\
& * \text { MINORITY }_{k}+\gamma_{005} * \text { SCHOOL CLIMATE }_{k} \\
& +\gamma_{100} * \text { WHITE }_{i j k}+\gamma_{200} * \text { MALE }_{i j k} \\
& * \text { OLDER }_{i j k}+\gamma_{400} * \mathrm{CHRONIC}_{i j k}+\gamma_{500} \\
& * \mathrm{SAFE}_{i j k}+\gamma_{600} * \mathrm{CONNECT}_{i j k}+\gamma_{700} \\
& * \mathrm{STUDENTSTOP}_{i j k}+\gamma_{800} \\
& * \text { ADULTSTOP }_{i j k}+r_{0 j k}+u_{00 k} \cdot
\end{aligned}
$$

While the primary model included gender as a covariate and allowed for an understanding of gender differences in the choice of response to bullying, post hoc analyses used interaction terms to examine gender as a moderator of the association between contextual perceptions (e.g., bystander intervention, safety, and connectedness) and response to victimization. As suggested by Jaccard and Turrisi, all continuous variables were mean-centered prior to the creation of interaction terms to avoid potential issues with collinearity when testing for interactions among variables [63].

\section{Results}

6.1. Differences by Victimization Status. Victims of bullying were more likely to be white, female, and younger than nonvictims (see Table 1 for test statistics and $P$ values). They were also less likely to believe that students and adults would intervene to stop bullying. Additionally, victims had significantly poorer perceptions of school safety and reported less connection to school than nonvictims.

6.2. Individual- and School-Level Influences on Aggressive Responses to Victimization. Minority students were more likely to report using an aggressive response to being victimized as compared to nonminority students (adjusted odds ratio $(\mathrm{AOR})=0.80, P<.001$; see Table 2$)$. Students in 11th and 12th grades were less likely to report using an aggressive response to being victimized as compared to 9 th and 10th graders $(\mathrm{AOR}=0.89, P<.05)$. Students who were victimized two or more times a month were $68 \%$ more likely to respond aggressively as compared to those who were victimized less frequently $(\mathrm{AOR}=1.68, P<.001)$. A more favorable perception of student intervention in bullying situations was associated with a reduced likelihood of responding aggressively $(\mathrm{AOR}=0.89, P<.05)$ but perception of adult intervention was not associated with the decision to respend aggressively. With regard to individuallevel perceptions of the school climate, students' perceptions of school safety and school connectedness were inversely associated with using an aggressive response when victimized $\left(\mathrm{AOR}_{\text {safe }}=0.65, P<.001 ; \mathrm{AOR}_{\text {connect }}=0.70, P<.001\right)$.

At the school level, schools with a higher overall percentage of minority youth were slightly less likely to report utilizing an aggressive response $(\mathrm{AOR}=0.996, P<.05)$.

In order to better understand the moderating role of gender, post hoc analyses were run using four interactions (i.e., gender $\times$ students intervene, gender $\times$ adults intervene, gender $\times$ safety, and gender $\times$ connectedness). Two significant interaction effects were identified. The interaction between gender and safety was significant $(\beta=-.16, P<.05)$ as well as the interaction between gender and connectedness $(\beta=$ $.21, P<.05)$. These findings indicated that for males higher perceptions of safety were more strongly associated with a reduced likelihood of retaliating than for females $(\mathrm{AOR}=.63$ for males versus $\mathrm{AOR}=.72$ for females). Conversely, higher perceptions of school connectedness were more strongly associated with a reduced likelihood of retaliating for females versus males $(\mathrm{AOR}=.76$ for males versus $\mathrm{AOR}=.62 \mathrm{for}$ females).

6.3. Individual- and School-Level Influences on Seeking Adult Support Responses. Males were less likely to report seeking adult support in response to being victimized as compared to females $(\mathrm{AOR}=0.76, P<.001$; see Table 2$)$. Students who were victimized 2 or more times a month were $87 \%$ more likely to respond by seeking adult support as compared to those who were victimized less frequently $(\mathrm{AOR}=1.87$, $P<.001)$. Although the perception that students intervene in bullying situations was not significantly associated with reports of seeking adult support to being victimized, the perception that adults would intervene was $(\mathrm{AOR}=1.13$, $P<.01)$. This suggests that youths who perceive that adults intervene with bullying are more likely to seek support from staff at the school when victimized. With regard to school climate, students who perceived their school to be more safe were significantly less likely to report seeking adult support $(\mathrm{AOR}=0.57, P<.001)$; however, student connectedness was not significantly associated with seeking adult support.

At the school level, schools with a higher overall percentage of minority youth were slightly less likely to report seeking adult support $(\mathrm{AOR}=0.993, P<.001)$. No significant interactions were found between gender and either bystander or school climate variables and the likelihood of seeking adult support. 
TABLE 2: HLM results for 3-level model examining the effect of school climate on responses to being bullied.

\begin{tabular}{|c|c|c|c|c|}
\hline & \multicolumn{2}{|c|}{ Aggressive response } & \multicolumn{2}{|c|}{ Adult support seeking } \\
\hline & OR & $\mathrm{CI}$ & OR & $\mathrm{CI}$ \\
\hline \multicolumn{5}{|l|}{ Student-level variables } \\
\hline White & $0.80^{* * *}$ & $(0.706,0.900)$ & 0.89 & $(0.759,1.034)$ \\
\hline Male & 1.11 & $(0.978,1.262)$ & $0.76^{* * *}$ & $(0.682,0.856)$ \\
\hline 11th and 12 th graders & $0.89^{*}$ & $(0.793,0.991)$ & 1.09 & $(0.907,1.302)$ \\
\hline Frequent victimization & $1.68^{* * *}$ & $(1.507,1.871)$ & $1.87^{* * *}$ & $(1.607,2.184)$ \\
\hline Students intervene & $0.92^{*}$ & $(0.860,0.989)$ & 1.01 & $(0.924,1.097)$ \\
\hline Adults intervene & 0.99 & $(0.933,1.050)$ & $1.13^{* *}$ & $(1.046,1.225)$ \\
\hline Safety & $0.65^{* * *}$ & $(0.584,0.726)$ & $0.57^{* * *}$ & $(0.519,0.633)$ \\
\hline Connectedness & $0.70^{* * *}$ & $(0.627,0.774)$ & 1.03 & $(0.895,1.189)$ \\
\hline \multicolumn{5}{|l|}{ School-level variables } \\
\hline Student-teacher ratio & 1.019 & $(0.999,1.040)$ & 0.994 & $(0.967,1.023)$ \\
\hline$\%$ Free and reduced meals & 1.003 & $(0.997,1.010)$ & 1.003 & $(0.994,1.013)$ \\
\hline$\%$ Suspension & 0.997 & $(0.991,1.002)$ & 1.001 & $(0.993,1.010)$ \\
\hline$\%$ Minority & $0.996^{*}$ & $(0.993,0.999)$ & $0.993^{* * *}$ & $(0.990,0.997)$ \\
\hline School climate & 0.961 & $(0.406,2.276)$ & 1.405 & $(0.668,2.955)$ \\
\hline Proportion variance explained & & $60.4 \%$ & & $81.5 \%$ \\
\hline
\end{tabular}

\section{Discussion}

The current study explored the association between school climate and different types of responses to bullying. The multi-level results suggested that bystander perceptions and school climate play a role in influencing students' responses to bullying, both by decreasing the likelihood of victims using an aggressive response and increasing their likelihood of seeking support from school staff. These modifiable aspects of the school environment appear to be potentially important determinants of bullying victims' responses to bullying. These findings highlight the importance of adopting a wholeschool approach to prevention, which encourages students and teachers to be aware of bullying and to assist victims [10]. Additionally, these findings may also support a broader focus on improving school climate in order to reduce bullying and the negative consequences of bullying.

This study adds to the literature by enhancing our understanding of individual variation in response to bullying victimization [11]. Consistent with the more general coping literature, male students were less likely to seek support from adults in their school than female students $[9,15,16]$. Interestingly they were not significantly more likely to use an aggressive response, which has also been widely supported in the more general coping literature $[15,17,18]$. Younger victimized students were more likely to use an aggressive response [64], which may reflect the general developmental trends in bullying, whereby it peaks in early adolescence $[23,65]$. Bullying that continues into late adolescence tends to be more relational than overt in nature, which may in turn influence victims' responses [23].

Minority students in this study were also more likely to respond by both using an aggresse response as well as seeking support. Studies attempting to understand racial differences in the prevalence of bullying have shown inconsistent results, possibly due to definition of bullying used. Sawyer et al. [66] found that African American youths who were bullied underreported victimization when a definitional measure of bullying was used. As the current study defined victimization using a similar definitional measure, it is possible that the minority youth included in the sample had quantitative or qualitatively different victimization experiences. More research, perhaps of a qualitative nature, needs to be done to explore racial differences in the experience of bullying [67]. This is further supported by the somewhat contradictory finding that, in higher minority schools, victims were less likely to both use an aggressive response and to tell an adult at school, a finding that suggests that in higher minority schools victims of bullying are more likely to use passive responses to bullying (e.g., walking away or doing nothing).

Students who were frequently bullied (i.e., two or more times in the past month) were more likely to report using both an aggressive response as well as telling an adult at school. Due to their multiple victimization experiences, these youths may have more opportunities to try out different responses to victimization, especially as the first response may have proven ineffective. These victimized youths might display what has been categorized as an undifferentiated response pattern following the experience of bullying, which has been associated with increased internalizing problems [11]. This finding suggests that highly victimized youth may be a particularly important group to target in bullying prevention both because of their increased exposure to bullying as well as due to the potential for their undifferentiated and ineffective response pattern to negatively influence school climate (e.g., through the use of aggressive responses) and their own mental health.

As hypothesized, greater perceptions of intervention by peers or adults in the school was related to decreased report 
of an aggressive response and increased report of seeking help from an adult. Interestingly a divaricated pattern emerged between perceptions of peer and school staff intervention and response to being bullied. Greater student intervention was related to a decreased aggressive response, but not a greater likelihood of seeking support from an adult. In contrast, greater perception of adult intervention was related to increased support seeking from school staff, but not a decreased aggressive response. This finding reinforces bullying prevention programs focus on those not involved in bullying. For peer bystanders, it suggests that their influence potentially extends beyond stopping the bullying situation [68], to influencing how victims' respond to their experience. Likewise, these findings support the need for additional teacher training on how to handle a bullying situation [26], as student perception of teacher intervention was associated with an increased likelihood of seeking help from adults.

Victims' perceptions of the school environment were also associated with their responses to being bullied. Students who felt that their school was unsafe were more likely to respond using aggression. As other researchers have hypothesized, unsafe environments may cause students to choose a retaliatory response to victimization as aggression becomes a school norm [22], and greater frequency of violence suggests that adults do not have control over the environment [37, 49]. This would further suggest that in safe environments students may be more likely to tell an adult about their victimization. Interestingly, this hypothesis was not supported, as victimized youths who felt their school was safer were less likely to report seeking help from an adult. Students in safer schools may feel that they have other options to respond to victimization, besides telling an adult, like telling their parent/guardian or a friend. Some studies have suggested that for high school students, telling an adult may not be an adaptive strategy for handling bullying in the social context [11]. In fact, it appears that high school youth may be more likely to instead seek support from a friend. More work is needed to explore developmental differences in the experience of bullying.

Another aspect of the school climate, students' connectedness, was associated with a decreased likelihood of responding aggressively to being bullied. Adolescent trust of teachers has been found to be important in promoting cooperative behavior and reducing defiant behavior in the classroom [69]. Although this would also suggest that connectedness would encourage victimized students to seek support from adults [50], our study did not find an association between students' connectedness to school and telling an adult at school. This may be because our measure of connectedness was broader than trust in adults and included items that assessed student belonging and peer relationships. As discussed previously, students who have higher levels of connectedness to the school may have other more developmentally adaptive ways of responding to bullying, including seeking support from friends [11].

We also performed some post hoc exploratory analyses to understand potential gender differences in the association between bystander and school climate perceptions and responses to bullying victimization. Although only two significant interactions were found, it is notable that these were both for the aggressive retaliation outcome and for factors related to the school climate (i.e., perceptions of safety and connectedness), rather than bystander variables. Perceptions of safety appeared to be associated with lower odds of males responding using aggression, whereas perceptions of connectedness appeared to be associated with lower odds of females responding using aggression. This finding is a potentially important one, as it suggests intervention points to potentially ameliorate gender differences in the use of adaptive (i.e., assertive) versus maladaptive (i.e., aggressive) strategies $[15,17,18,70,71]$. These results support the use of school climate interventions in both helping bullied students cope with victimization as well as stopping the cycle of violence.

Despite the value of this study, there are some limitations. For example, this study used cross-sectional data from a single time point; therefore, our findings are correlational and causation cannot be inferred. It is quite possible that bullied students' experiences of victimization negatively impacted their perceptions of the likelihood of bystander intervention as well as their impressions of school climate. Additionally, caution needs to be taken in generalizing these findings as they represent students from high schools across only one state. The final limitation comes due to the correlated nature of the data. Unfortunately this prevented us from being able to examine the influence of bystander behaviors and more specific aspects of school climate at the school level.

This study supports a role for bystanders and school climate in influencing bullying victims' response choice to victimization. School environments where victims perceive that students and school adults will intervene and where they feel safe and connected discourage a retaliatory response and encourage seeking help. Bullying prevention programs which focus on changing school norms about bullying appear to be important for not just the stopping of bullying but for helping victims respond as desired to bullying (i.e., tell an adult rather than retaliate). Our findings also suggest that interventions that focus more holistically on changing school climate (e.g., positive behavioral interventions and supports) may play a role in interrupting the cycle of violence [72].

\section{Acknowledgment}

This work was funded in part by grants from the US Department of Education and William T. Grant Foundation awarded to Catherine Bradshaw of Johns Hopkins University. The authors would like to thank the Maryland State Department of Education and Sheppard Pratt Health System for their support of this research through the Maryland Safe and Supportive Schools Project.

\section{References}

[1] Centers for Disease Control, Youth Risk Behavior Surveillance Survey, 2011.

[2] T. R. Nansel, M. Overpeck, R. S. Pilla, W. J. Ruan, B. SimonsMorton, and P. Scheidt, "Bullying behaviors among US youth: prevalence and association with psychosocial adjustment," 
Journal of the American Medical Association, vol. 285, no. 16, pp. 2094-2100, 2001.

[3] K. Stassen Berger, "Update on bullying at school: science forgotten?” Developmental Review, vol. 27, no. 1, pp. 90-126, 2007.

[4] E. S. Buhs, G. W. Ladd, and S. L. Herald, "Peer exclusion and victimization: processes that mediate the relation between peer group rejection and children's classroom engagement and achievement?" Journal of Educational Psychology, vol. 98, no. 1, pp. 1-13, 2006.

[5] M. M. Ttofi and D. P. Farrington, "Effectiveness of school-based programs to reduce bullying: a systematic and meta-analytic review," Journal of Experimental Criminology, vol. 7, no. 1, pp. 27-56, 2011.

[6] B. A. Schroeder, A. Messina, D. Schroeder et al., "The implementation of a statewide bullying prevention program: preliminary findings from the field and the importance of coalitions," Health Promotion Practice, vol. 13, no. 4, pp. 489-495, 2012.

[7] S. C. Hunter and J. M. E. Boyle, "Appraisal and coping strategy use in victims of school bullying," British Journal of Educational Psychology, vol. 74, no. 1, pp. 83-107, 2004.

[8] B. Kochenderfer-Ladd, "Identification of aggressive and asocial victims and the stability of their peer victimization," MerrillPalmer Quarterly, vol. 49, no. 4, pp. 401-425, 2003.

[9] B. Kochenderfer-Ladd and K. Skinner, "Children's coping strategies: moderators of the effects of peer victimization?" Developmental Psychology, vol. 38, no. 2, pp. 267-278, 2002.

[10] D. Olweus, "Bully/victim problems among schoolchildren: long-term consequences and an effective intervention program," in Mental Disorder and Crime, S. Hodgins, Ed., pp. 317349, Sage, Newbury Park, Calif, USA, 1993.

[11] T. E. Waasdorp and C. P. Bradshaw, "Examining student responses to frequent bullying: a latent class approach," Journal of Educational Psychology, vol. 103, no. 2, pp. 336-352, 2011.

[12] L. C. Elledge, T. A. Cavell, N. T. Ogle, K. T. Malcolm, R. A. Newgent, and M. A. Faith, "History of peer victimization and children's response to school bullying," School Psychology Quarterly, vol. 25, no. 2, pp. 129-141, 2010.

[13] V. Pöyhönen, J. Juvonen, and C. Salmivalli, "What does it take to stand up for the victim of bullying? The interplay between personal and social factors," Merrill-Palmer Quarterly, vol. 56, no. 2, pp. 143-163, 2010.

[14] C. Salmivalli, J. Karhunen, and K. M. J. Lagerspetz, "How do the victims respond to bullying?” Aggressive Behavior, vol. 22, no. 2, pp. 99-109, 1996.

[15] H. Eschenbeck, C.-W. Kohlmann, and A. Lohaus, "Gender differences in coping strategies in children and adolescents," Journal of Individual Differences, vol. 28, no. 1, pp. 18-26, 2007.

[16] C. E. Roecker Phelps, “Children's responses to overt and relational aggression," Journal of Clinical Child and Adolescent Psychology, vol. 30, no. 2, pp. 240-252, 2001.

[17] P. Hampel and F. Petermann, "Age and gender effects on coping in children and adolescents," Journal of Youth and Adolescence, vol. 34, no. 2, pp. 73-83, 2005.

[18] S. M. Kristensen and P. K. Smith, "The use of coping strategies by Danish children classed as bullies, victims, bully/victims, and not involved, in response to different (hypothetical) types of bullying," Scandinavian Journal of Psychology, vol. 44, no. 5, pp. 479-488, 2003.

[19] R. S. Atlas and D. J. Pepler, "Observations of bullying in the classroom," The Journal of Educational Research, vol. 92, no. 2, pp. 86-98, 1998.
[20] S. R. Lindstrom Johnson, N. M. Finigan, C. P. Bradshaw, D. L. Haynie, and T. L. Cheng, "Examining the link between neighborhood context and parental messages to their adolescent children about violence," Journal of Adolescent Health, vol. 49, no. 1, pp. 58-63, 2011.

[21] H. Cowie and R. Olafsson, "The role of peer support in helping the victims of bullying in a school with high levels of aggression," School Psychology International, vol. 21, no. 1, pp. 79-95, 2000.

[22] J. D. Unnever and D. G. Cornell, "The culture of bullying in middle school," Journal of School Violence, vol. 2, no. 2, pp. 527, 2003.

[23] C. P. Bradshaw, A. L. Sawyer, and L. M. O’Brennan, "Bullying and peer victimization at school: perceptual differences between students and school staff," School Psychology Review, vol. 36, no. 3, pp. 361-382, 2007.

[24] R. M. Novick and J. Isaacs, "Telling is compelling: the impact of student reports of bullying on teacher intervention," Educational Psychology, vol. 30, no. 3, pp. 283-296, 2010.

[25] J. S. Yoon, E. Barton, and J. Taiariol, "Relational aggression in middle school: educational implications of developmental research," The Journal of Early Adolescence, vol. 24, no. 3, pp. 303-318, 2004.

[26] C. P. Bradshaw et al., 'Teachers' and education support professionals' perspectives on bullying and prevention: findings from a National Education Association (NEA) survey," School Psychology Review. In press.

[27] D. L. Hawkins, D. J. Pepler, and W. M. Craig, "Naturalistic observations of peer interventions in bullying," Social Development, vol. 10, no. 4, pp. 510-527, 2001.

[28] M. M. Ttofi and D. Farrington, "Bullying prevention programs: the importance of peer intervention, disciplinary methods and age variations," Journal of Experimental Criminology, vol. 8, no. 4, pp. 443-462, 2012.

[29] J. R. Polanin, D. L. Espelage, and T. D. Pigott, "A metaanalysis of school-based bullying prevention programs' effects on bystander intervention behavior," School Psychology Review, vol. 41, no. 1, pp. 47-65, 2012.

[30] M. J. Boulton, M. Trueman, and I. Flemington, "Associations between secondary school pupils' definitions of bullying, attitudes towards bullying, and tendencies to engage in bullying: age and sex differences," Educational Studies, vol. 28, no. 4, pp. 353-370, 2002.

[31] K. Rigby and B. Johnson, "Expressed readiness of Australian schoolchildren to act as bystanders in support of children who are being bullied," Educational Psychology, vol. 26, no. 3, pp. 425-440, 2006.

[32] K. Rigby and P. T. Slee, "Bullying among Australian school children: reported behavior and attitudes toward victims," The Journal of Social Psychology, vol. 131, no. 5, pp. 615-627, 1991.

[33] I. Whitney and P. K. Smith, "A survey of the nature and extent of bullying in junior/middle and secondary schools," Educational Research, vol. 35, no. 1, pp. 3-25, 1993.

[34] C. Salmivalli, M. Lappalainen, and K. M. J. Lagerspetz, "Stability and change of behavior in connection with bullying in schools: a two-year follow-up," Aggressive Behavior, vol. 24, no. 3, pp. 205218, 1998.

[35] J. Trach, S. Hymel, T. Waterhouse, and K. Neale, "Bystander responses to school bullying: a cross-sectional investigation of grade and sex differences," Canadian Journal of School Psychology, vol. 25, no. 1, pp. 114-130, 2010. 
[36] M. Sainio, R. Veenstra, G. Huitsing, and C. Salmivalli, "Victims and their defenders: a dyadic approach," International Journal of Behavioral Development, vol. 35, no. 2, pp. 144-151, 2011.

[37] C. P. Bradshaw, A. L. Sawyer, and L. M. O’Brennan, "A social disorganization perspective on bullying-related attitudes and behaviors: the influence of school context," American Journal of Community Psychology, vol. 43, no. 3-4, pp. 204-220, 2009.

[38] C. P. Bradshaw and T. E. Waasdorp, "Measuring and changing a 'culture of bullying"' School Psychology Review, vol. 38, no. 3, pp. 356-361, 2009.

[39] R. J. Sampson and W. B. Groves, "Community structure and crime: testing social-disorganization theory," American Journal of Sociology, vol. 94, no. 4, pp. 774-802, 1989.

[40] R. J. Sampson, S. W. Raudenbush, and F. Earls, "Neighborhoods and violent crime: a multilevel study of collective efficacy," Science, vol. 277, no. 5328, pp. 918-924, 1997.

[41] T. Leventhal and J. Brooks-Gunn, "The neighborhoods they live in: the effects of neighborhood residence on child and adolescent outcomes," Psychological Bulletin, vol. 126, no. 2, pp. 309-337, 2000.

[42] A. A. Payne, D. C. Gottfredson, and G. D. Gottfredson, "Schools as communities: the relationships among communal school organization, student bonding, and school disorder," Criminology, vol. 41, no. 3, pp. 749-777, 2003.

[43] S. B. Plank, C. P. Bradshaw, and H. Young, "An application of "Broken-windows" and related theories to the study of disorder, fear, and collective efficacy in schools," American Journal of Education, vol. 115, no. 2, pp. 227-247, 2009.

[44] C. W. Koth, C. P. Bradshaw, and P. J. Leaf, "A multilevel study of predictors of student perceptions of school climate: the effect of classroom-level factors," Journal of Educational Psychology, vol. 100, no. 1, pp. 96-104, 2008.

[45] A. Kitsantas, H. W. Ware, and R. Martinez-Arias, "Students' perceptions of school safety: effects by community, school environment, and substance use variables," The Journal of Early Adolescence, vol. 24, no. 4, pp. 412-430, 2004.

[46] P. Wilcox, M. C. Augustine, and R. R. Clayton, "Physical environment and crime and misconduct in Kentucky schools," The Journal of Primary Prevention, vol. 27, no. 3, pp. 293-313, 2006.

[47] A. Bandura, "Social learning theory of aggression," Journal of Communication, vol. 28, no. 3, pp. 12-29, 1978.

[48] R. Huesmann, N. G. Guerra, L. S. Miller, and A. Zelli, "The role of social norms in the development of aggressive behavior, in socialization and aggression," H. Zumkley and A. Fraczek, Eds., Springer, New York, NY, USA, 1992.

[49] A. S. Birnbaum, L. A. Lytle, P. J. Hannan, D. M. Murray, C. L. Perry, and J. L. Forster, "School functioning and violent behavior among young adolescents: a contextual analysis," Health Education Research, vol. 18, no. 3, pp. 389-403, 2003.

[50] M. Eliot, D. Cornell, A. Gregory, and X. Fan, "Supportive school climate and student willingness to seek help for bullying and threats of violence," Journal of School Psychology, vol. 48, no. 6, pp. 533-553, 2010.

[51] G. P. Kuperminc, B. J. Leadbeater, C. Emmons, and S. J. Blatt, "Perceived school climate and difficulties in the social adjustment of middle school students," Applied Developmental Science, vol. 1, no. 2, pp. 76-88, 1997.

[52] Centers for Disease Control, "Bullying surveillance among school-age children: uniform definitions and recommended data elements," In press.
[53] C. P. Bradshaw, T. E. Waasdorp, A. Goldweber, and S. L. Johnson, "Bullies, gangs, drugs, and school: Understanding the overlap and the role of ethnicity and urbanicity," Journal of Youth and Adolescence, vol. 42, no. 2, pp. 220-234, 2013.

[54] T. E. Waasdorp, C. P. Bradshaw, and J. Duong, "The link between parents' perceptions of the school and their responses to school bullying: variation by child characteristics and the forms of victimization," Journal of Educational Psychology, vol. 103, no. 2, pp. 324-335, 2011.

[55] M. D. Resnick, P. S. Bearman, R. W. Blum et al., "Protecting adolescent's from harm: findings from the national longitudinal study on adolescent health," Journal of the American Medical Association, vol. 278, no. 10, pp. 823-832, 1997.

[56] U. S. Department of Education, Safe and Supportive Schools, 2009, http://safesupportiveschools.ed.gov/index.php?id=33.

[57] S. Lindstrom Johnson, C. P. Bradshaw, and K. Debnam, "Promoting data-driven evidence-based program implementation: the maryland safe and supportive schools project," in Proceddings of the Society for Prevention Research, Washington, DC, USA, 2012.

[58] J. L. Arbuckle and W. Wothke, AMOS 4.0 User's Guide, Small Waters Corporation, Chicago, Ill, USA, 1999.

[59] S. W. Raudenbush, A. S. Bryk, Y. F. Cheong, R. Congdon, and M. $\mathrm{du}$ Toit, Hierarchical Linear and nonLinear Modeling (HLM7), Scientific Software International, Lincolnwood, Ill, USA, 2011.

[60] J. L. Schafer and J. W. Graham, "Missing data: our view of the state of the art," Psychological Methods, vol. 7, no. 2, pp. 147-177, 2002.

[61] S. W. Raudenbush and A. S. Bryk, Hierarchical Linear Models: Applications and Data Analysis Methods, Sage, Thousand Oaks, Calif, USA, 2nd edition, 2002.

[62] C. K. Enders and D. Tofighi, "Centering predictor variables in cross-sectional multilevel models: a new look at an old issue," Psychological Methods, vol. 12, no. 2, pp. 121-138, 2007.

[63] J. Jaccard and R. Turrisi, Interaction Effects in Multiple Regression, Sage University Papers Series, Sage, Newbury Park, Calif, USA, 2nd edition, 2003.

[64] C. L. Fox and M. J. Boulton, "The social skills problems of victims of bullying: self, peer and teacher perceptions," British Journal of Educational Psychology, vol. 75, no. 2, pp. 313-328, 2005.

[65] D. Olweus, Bullying at School, Blackwell, Oxford, UK, 1993.

[66] A. L. Sawyer, C. P. Bradshaw, and L. M. O’Brennan, "Examining ethnic, gender, and developmental differences in the way children report being a victim of "Bullying" on self-report measures," Journal of Adolescent Health, vol. 43, no. 2, pp. 106$114,2008$.

[67] A. Goldweber, T. Waasdorp, and C. Bradshaw, "Examining associations between race, urbanicity, and patterns of bullying involvement," Journal of Youth and Adolescence, vol. 42, no. 2, pp. 206-219, 2013.

[68] C. Salmivalli, K. Lagerspetz, K. Bjorkqvist, K. Osterman, and A. Kaukianinen, "Bullying as a group process: participant roles and their relations to social status within the group," Aggressive Behavior, vol. 22, no. 1, pp. 1-15, 1996.

[69] A. Gregory and M. B. Ripski, "Adolescent trust in teachers: implications for behavior in the high school classroom," School Psychology Review, vol. 37, no. 3, pp. 337-353, 2008.

[70] M. Camodeca and F. A. Goossens, "Children's opinions on effective strategies to cope with bullying: the importance of bullying role and perspective," Educational Research, vol. 47, no. 1, pp. 93-105, 2005. 
[71] W. Craig, D. Pepler, and J. Blais, "Responding to bullying: what works?” School Psychology International, vol. 28, no. 4, pp. 465477, 2007.

[72] C. P. Bradshaw, C. W. Koth, L. A. Thornton, and P. J. Leaf, "Altering school climate through school-wide positive behavioral interventions and supports: findings from a group-randomized effectiveness trial," Prevention Science, vol. 10, no. 2, pp. 100-115, 2009. 

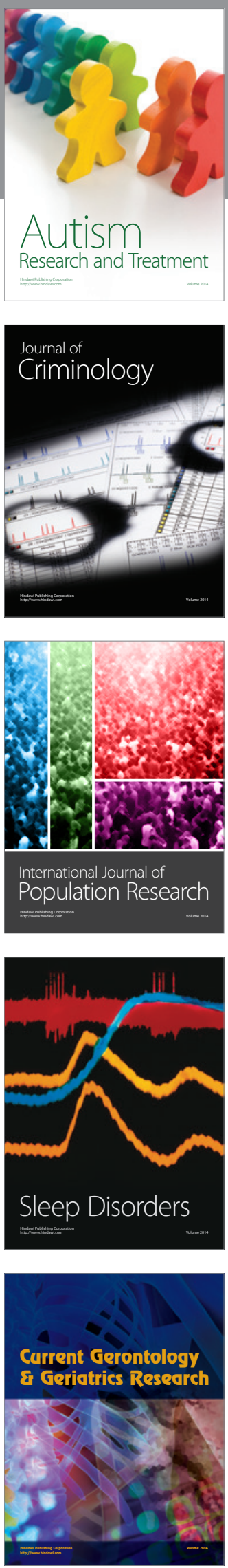
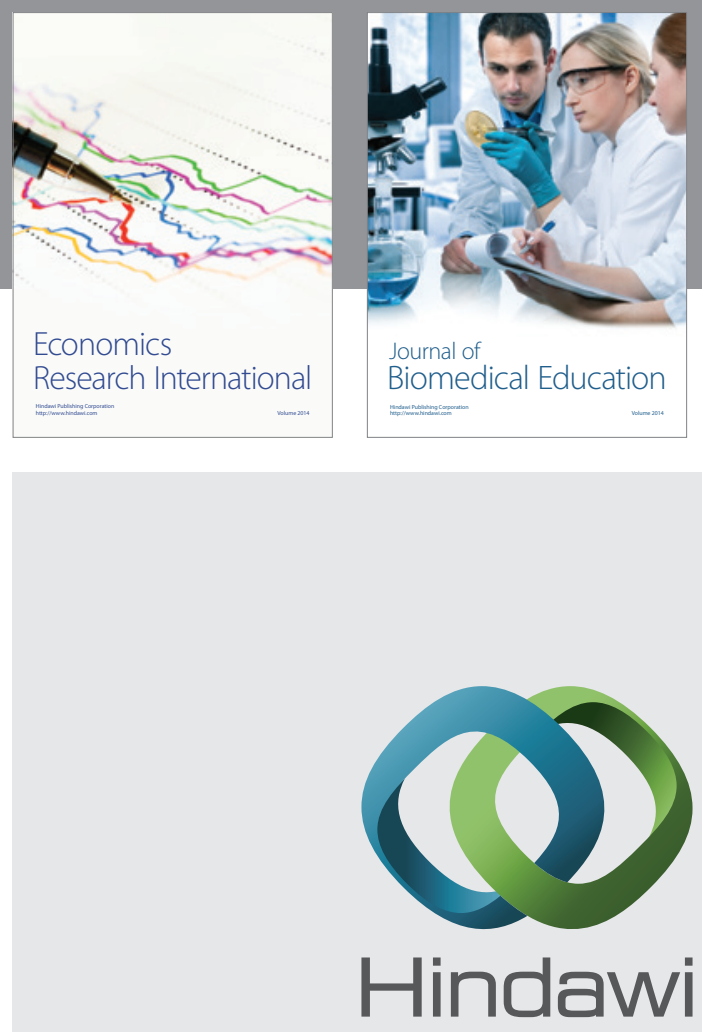

Submit your manuscripts at

http://www.hindawi.com
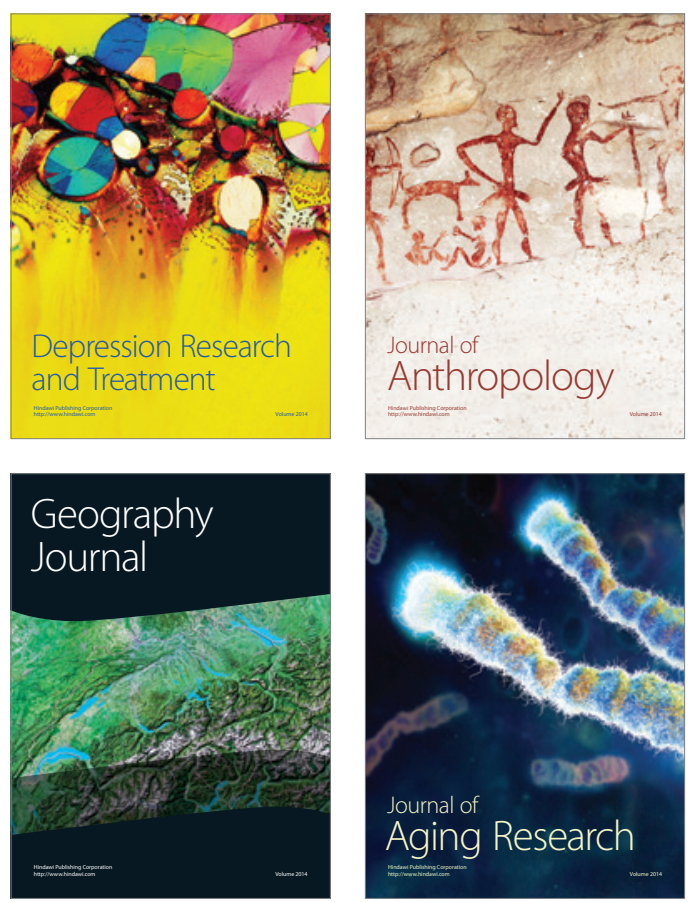
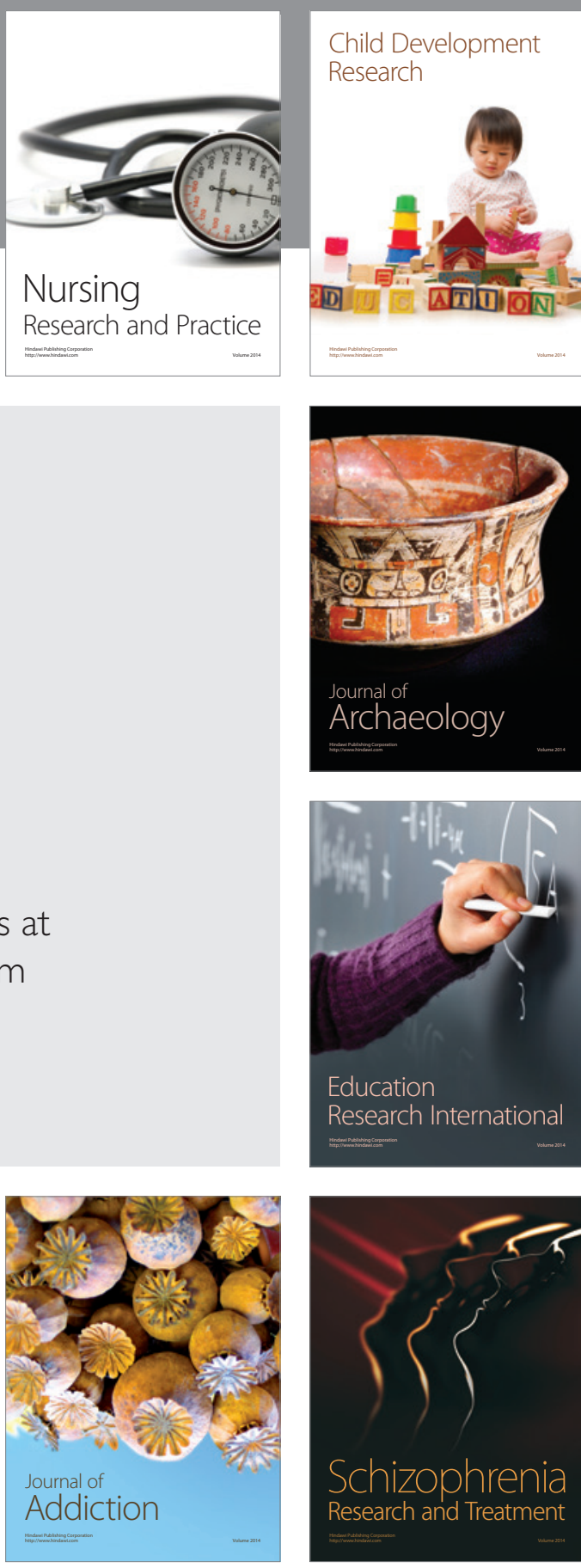

(D)
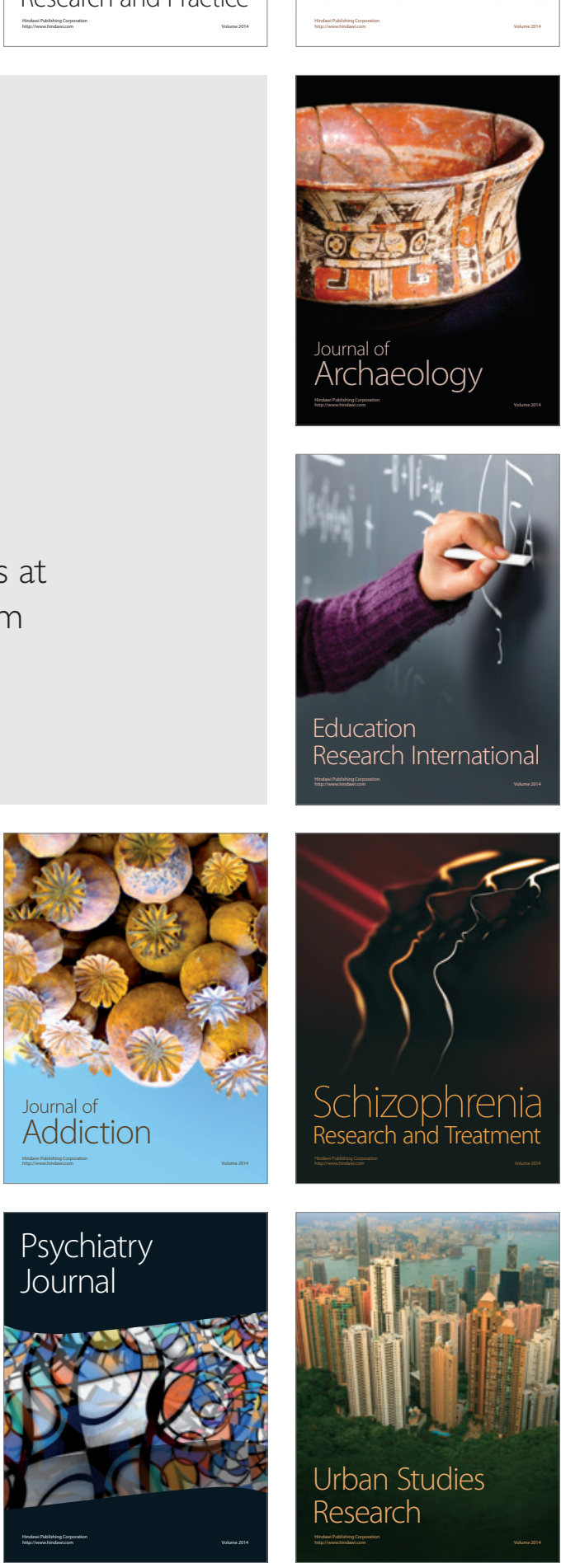